\title{
Emergency Surgical Retrieval of an Amplatzer Septal Occluder Device Embolization
}

\section{Noureddine Atmani* , Julia Mitchell, Olivier Metton, Jean Ninet}

Service de chirurgie des cardiopathies congénitales, hôpital cardiologique Louis Pradel, Lyon, France

*Corresponding Author: Noureddine Atmani, Service de chirurgie des cardiopathies congénitales, hôpital cardiologique Louis Pradel, Lyon, France, E-mail: dratmani@hotmail.fr

Received: 27 November 2017; Accepted: 04 December 2017; Published: 07 December 2017

\begin{abstract}
Atrial septal defect (ASD) is a common congenital heart defect. Transcatheter closure become now the standard approach for ostium secondum type ASD closure against surgery. However, this procedure is not free of complications Device migration is the most common complication. We report a case of an obstruction of tricuspid valve by migration of a transcatheter ASD device occlude in a 9 years-old girl reveled by severe ventricular arrhythmias. She underwent successful emergent surgical removal under cardiopulmonary bypass and ASD closure with a synthetic patch. The postoperative course was favorable.
\end{abstract}

Keywords: Atrial septal defect; Cardiovascular malformation

\section{Introduction}

Atrial septal defect (ASD) is a common congenital heart defect, it represent $10-15 \%$ of all cardiovascular malformation [1]. Surgery has been considered to be the gold standard treatment of ASD since the late 1960s with good long term postoperative results [2]. The first transcatheter closure of ASD was conducted by King and Mills in 1976 [3], it become now the standard approach for ostium secundum type ASD closure because it is technically simple and associated with low mortality and morbidity, as well as shorter hospital stay and recovery. However, several studies have reported a post-procedural in-hospital complication rate ranging from $1.2-8.7 \%$. Device migration is the most common complication $[2,4,5,6]$ percutaneous device retrieval is not possible in most cases and surgical removal is necessary. We report a case of an obstruction of tricuspid valve by migration of a transcatheter ASD device occluder reveled by a severe ventricular arrhythmia. 


\section{Observation}

We report an observation of a 9 year-old girl referred for an cardiac murmur. Clinical examination found a child in good health weighing $22 \mathrm{~kg}$. The cardiac auscultation found a 2/6 pulmonic ejection systolic murmur associated with a duplicated second pulmonary sound. The transthoracic echocardiography (TTE) reported an ostium secondum ASD measuring 15.3x18.2 mm with a right to left shunt estimating the QP/QS ratio at 2. The posterior and superior rims are in good size but the aortic and inferior rims are less than $5 \mathrm{~mm}$. The right cavities are dilated and the pulmonary pressures are infra-systemic. She underwent transcatheter closure under general anesthesia. The pressures were measured in right atrium (RA) at $13 \mathrm{mmHg}$, in left atrium (LA) at $14 \mathrm{mmHg}$, in right ventricle (RV) at $28 / 5 \mathrm{mmHg}$ and in pulmonary artery (PA) at 27/12 $\mathrm{mmHg}$. The implantation of a $26 \mathrm{~mm}$ Amplatzer prosthesis was successful after several deployment attempts. The per-procedure transesophageal echocardiography (TEE) was satisfactory. After 12 hours, the child presented with palpitations associated with sweating and pallor. The electrocardiogram showed transient ventricular tachycardia (VT). The TTE showed a migration of the prosthesis through the tricuspid valve wish obstructed the inlet portion of the RV, in Doppler examination there were a severe tricuspid insufficiency. The child was emergently admitted to the operating room. After a mini-sternotomy and under cardiopulmonary bypass (CPB) with cardiac arrest. Right atriotomy showed a large ASD with a normal pulmonary venous return. The postero-inferior and aortic rims are less than $5 \mathrm{~mm}$. The amplatzer was found in the $\mathrm{RV}$ attached to the tricuspid septal leaflet (Figure 1). The prosthesis was removed without valvular lesions. The ASD was closed with a PTFE patch. The postoperative TTE showed the absence of residual shunt and a normal tricuspid valve function. The child was discharged after 7 days.

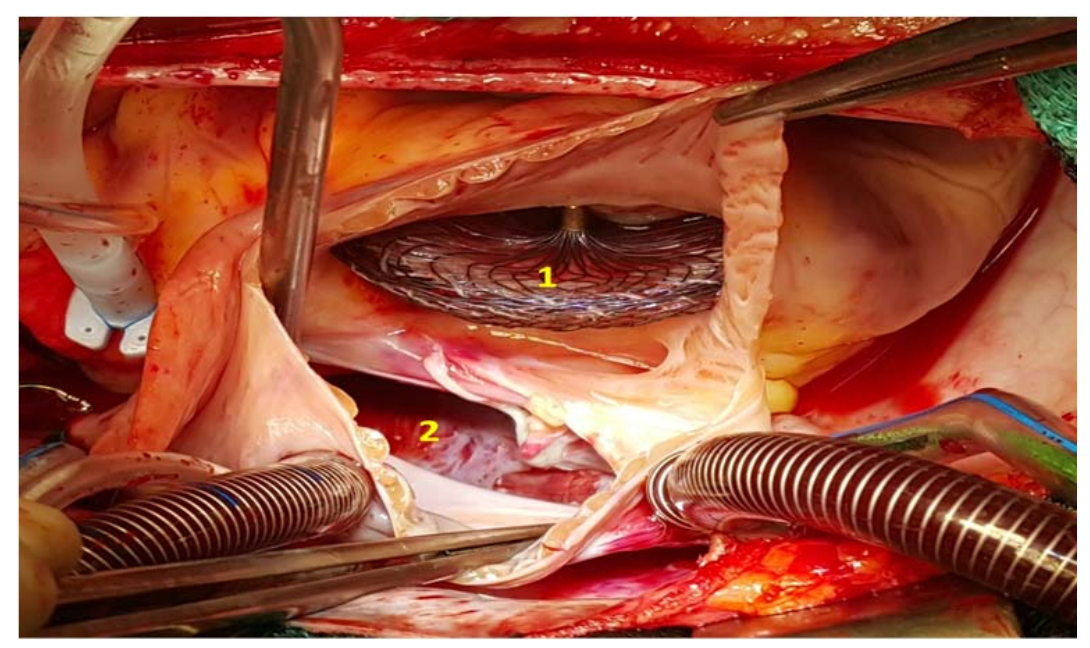

Figure 1: Operative show: 1 - Transtricuspid Amplatzer Device Migration; 2- Atrial Septal Defect

\section{Discussion}

Atrial septal defect (ASD) is the third most common congenital heart disease and accounts for approximately 6\% to $10 \%$ of all congenital cardiac defects [7]. Surgery has been considered to be the standard treatment of ASD for several decades with high success rate, low mortality and good long term postoperative results [8]. Since its introduction by King and Mills in 1976 [3], Interventional trans-catheter closure for ASD became a standard technique against surgery for nearly two decades all over the world. Device closure has evolved significantly, the 
Amplatzer septal occluder (ASO) has become the most commonly used device [9]. It offers the advantage that it obviates thoracotomy scars and open heart surgery. Recent studies emphasizes that trans-catheter closure is a safe method with shorter hospital stay, less mortality and morbidity rates [10]. However, this procedure is not free of complications. Device embolization is the most frequent major complication after ASO. In the literature, embolization rates were high ranging from $4 \%$ to $20 \%$, actually it decreased between 0.55 and $2 \%$ with new generation devices [9].

Embolization of the device may occur in intra-cardiac sites (left atrium, right atrium, left ventricle or right ventricle) or extra-cardiac sites such pulmonary and aortic arteries and may cause serious damages.

Clinical presentation is depending of device embolization site. In the majority of cases, device embolization is asymptomatic. In our case, the clinical manifestation was a severe ventricular arrhythmia because of the location in the right ventricle $[3,4]$.

The principal cause of device embolization is the inadequate defect rim to hold the device or tearing of the interatrial septum especially at the lower rim of the ASD owing to catheter and device manipulations. Several study report that larger ASD (> $20 \mathrm{~mm}$ ) and device size (> $24 \mathrm{~mm}$ ) were the most predictors factors related to device embolization which were seen in our patient [5]. Misra $\mathrm{M}$ et al. [11] reports that small or deficient aortic rim is often ignored with newer self-centering devices. However, a margin less than $5 \mathrm{~mm}$ may predispose to early and late device embolization. Others reports have showed a deficient aortic rim in the majority of cases associated with embolization or displacement of the device. [2,5]

Currently no guidelines exist for device embolization management. Several studies report a successful percutaneous retrieval of embolized device when the embolization site occurs in extracardiac. Moreover, in intracardiac embolization, percutaneous retrieval attempts may cause intracardiac structure damage particularly at valvular and subvalvular apparatus. Gokhan Gokaslan [9] report tricuspid septal leaflet chordae injury in two cases and posterior leaflet septal commissural damage in one case needing surgical repair. We believe that surgical intervention is a secure option for management of intracardiac embolization particularly when patient is symptomatic, as our case. We preferred emergency intervention because of the localization of the embolized device in tricuspid valve and the presence of ventricular arrhythmia.

\section{Conclusion}

Our case showed that transcatheter atrial septal occlude is not without risk. Device embolization is the most frequent complication. It can be reveled by severing clinical manifestation, such as ventricular arrhythmia, related to the immobilized device location. Surgical management is a secure option in intracardiac embolization in absent of guidelines for device embolization management. 


\section{References}

1. Van der Linde D, Konings EE, Slager MA, Witsenburg M, Helbing WA, Takkenberg JJ et al. Birth prevalence of congenital heart disease worldwide: a systematic review and meta-analysis. J Am Coll Cardiol 58 (2011): 2241-2247.

2. Tanghöj G, Odermarsky M, Naumburg E, Liuba P. Early Complications After Percutaneous Closure of Atrial Septal Defect in Infants with ProceduralWeight Less than 15 kg. Pediatr Cardiol 38 (2017): 255-263.

3. King TD, Thompson SL, Steiner C, Mills NL. Secundum atrialvseptal defect. Nonoperative closure during cardiac catheterization. JAMA 235 (1976): 2506-2509.

4. Yared K, Baggish AL, Solis J, Durst R, Passeri JJ, Palacios IF et al. Echocardiographic assessment of percutaneous patent foramen ovale and atrial septal defectclosure complications. Circ Cardiovasc Imaging 2 (2009): 141-149.

5. Wu HC, Wang CC, Fu YC, Jan SL, Wei HJ, Lin YK et al. Surgical Management for Complications during Closure of Atrial Septal Defect with Amplatzer Device. Acta Cardiol Sin 29 (2013): 557-561.

6. Gaspardone A, Iani C, Papa M. Percutaneous closure of patent foramen ovale: a wise approach [in Italian]. G Ital Cardiol (Rome) 9 (2008): 593-602.

7. Dickinson DF, Arnold R, Wilkinson JL. Congenital heart disease among 160,480 live-born children in Liverpool 1960 to 1969 (Implications for surgical treatment) . Br Heart J 46 (1981): 55-62.

8. Behjati M, Rafiei M, Soltani MH, Emami M, Dehghani M.Transcatheter closure of atrial septal defect with amplatzer septal occluder in adults: immediate, short, and intermediate-term results. J Tehran Heart Cent 6 (2011): 79-84.

9. Gokaslan G, Ustunsoy H, Deniz H, Ozcaliskan O, Yasim A, Baspinar O et al. Urgent surgical management for embolized occluder devices in childhood: single centerexperience. J Cardiothorac Surg 7 (2012): 127.

10. Bialkowski J, Karwot B, Szkutnik M, Banaszak P, Kusa J, Skalski J. Closure of atrial septal defects in children: surgery versus Amplatzer device implantation. Tex Heart Inst J 31 (2004): 220-223.

11. Misra M, Sadiq A, Namboodiri N, Karunakaran J. The ‘aortic rim’ recount: embolization of interatrial septal occluder into the main pulmonary artery bifurcation after atrial septal defect closure. Interact Cardiovasc Thorac Surg 6 (2007): 384-386

This article is an open access article distributed under the terms and conditions of the

Creative Commons Attribution (CC-BY) license 4.0 